\title{
Research on the Cultural Equivalence in Translation
}

\author{
Siyu Zou \\ Nanchang Institute of Technology
}

Keywords: Cultural focus; Semantic vacancy; Culture loaded words; Equivalence

\begin{abstract}
Translation is difficult, because the language reflects culture, carries the rich cultural connotations and is influenced by cultural constraints. So what is culture? What the relationship of it with translation? This paper discusses the cultural characteristics, the role of culture in translation, the reasons for the loss and distortion of cultural images in translation and how to overcome and deal with the cultural barriers. From the perspective of cultural translation, this paper explores the function of cultural factors in translation, the different thought in translation from a cultural perspective view and hot to eliminate cultural perplexity to achieve cultural equivalence in translation as much as possible.
\end{abstract}

\section{Introduction}

Some difficulties in translation are from cultural characteristics. If the translation is the meaning transfer between a set of specific symbols of a kind of culture and a set of specific symbols of another kind of culture, the degree of cultural differences in some degree determines the complex degree of translation. Every nation has their own cultural focus. Vocabulary is always towards specific culture in the focus direction. If the focuses of culture are similar, then the semantic correspondence and cross of the vocabulary of different language in different culture are widespread; On the contrary, if the cultural focuses are different, then the semantic conflict or lexical will be very prominent, the difficulty of translation will increase greatly. Therefore, when literature contains a lot of culture-loaded words with huge difference, then the difficulty of the language translation between languages increases, because it is difficult for translators to find ready-made and corresponding expression. From the perspective of cultural translation, this paper explores the function of cultural factors in translation, the different thought in translation from a cultural perspective view and hot to eliminate cultural perplexity to achieve cultural equivalence in translation as much as possible.

\section{Characteristics of Culture}

Culture is a complex whole which includes knowledge, belief, art, morals, law, customs and any skills and habits which a person obtain as a member of the society. It is human acquired an human shared. The characteristics of culture are:

1. Hyper physiological and transpersonal: Hyper physiological refers that any culture is acquired and created by people after born. Culture cannot be produced by physiological inheritance. Transpersonal refers that although the individual has the ability to accept culture and to create culture, the power to form the culture is not from individual. Only when the individual interacts with other, is the culture needed, accepted and influenced.

2. Any kind of cultural phenomenon is not isolated, but combines with a variety of cultural elements.

3. Cultural phenomenon always has the extensive meaning. The significance of culture is far beyond the narrow range which is directly shown by cultural phenomenon.

4. Culture was born to be imitated and used by others, including vertical transmission (from generation to generation) and lateral transfer (between region and nation).

5. The changing and the lagging: The changing nature is that the culture is not static and is in change. It is generally believed that the large-scale cultural changes have three factors, firstly, changes in natural conditions, such as natural disasters and population changes; secondly, contacts 
between different cultures, such as the changes of different countries, ethnic and nationality, lifestyle, values, etc.; thirdly, inventions and discoveries bring great changes in human society and culture. The lagging refers to the various parts of the culture have different speed in the change, leading to the imbalance, difference and dislocated between the parts.

\section{Literary Translation}

Dynamic equivalence is functional in nature. In order to reduce the translation loss to the lowest, the translator shall make necessary compensation in translation. In the translation of literary discourse, the cultural difficulties in the context create obstacle for translators. Translators shall make the necessary compensation for cultural default.

Dynamic equivalence emphasizes the equivalence of meaning, so the translator must convey the meaning of the original rather than the form, and cannot ignore the representation of the style. In poetry translation, the translator shall retain the "essence" and reproduce the "taste" of the original poem." Taste " is the personality characteristic which is unique to a poem and makes readers have the deepest feelings, such as the theme, artistic conception, momentum, special rhythm, writing and poetry, etc. Considering from reader effect, the translation which retains the "taste" of the original poem shall give readers the same artistic infection as the original poem does and cause similar resonance in the reader's mind. The follows is a section of Rubaiyat of Omar Khayyam translated by Guo Moruo.

Awake! For Morning in thd Bowl of Night
Has flung the Stone that Puts thd stats to flight:
And Lo! The Hunter of the East has caught
The Sultan's Turret in a Noose of Light
醒呀!太阳驱散了群星
暗夜从空中逃遁
灿烂的金箭
射中了苏丹的高扳。

Mr. Wen Yiduo considered the translation of Guo Moruo as "the magic work" and considered the poem was very difficult to translate due to the syntax of the cascade, the complexity of rhetoric, and the absurdity of the East. The "spirit" of the poem is located here. The translator seized it, skillfully eliminated some cumbersome rhetoric and cleverly translated it. It can be seen that Wen Yiduo advocated that the most important of the translation of poems is not the linguistic equivalent transform, but "to catch the original poem spirit" to embody the spirit of the original poem.

\section{Cultural Equivalence in Translation}

The close relationship between language and culture is destined to the close relationship between translation and culture. Using two languages has always been considered to be a basic requirement of translators, because the process of translation is to transfer a kind of language into another. In the process, the culture of the two languages must be involved. We often see the text easily, but the translation is wrong due to the lack of understanding of the source language culture. For example, "rest room" in big stores of America or international airport is translated into "the room for rest", but not "the toilet". So a kind of language cannot be really mastered with knowing the social culture of the language.

Translation is not as easy as many people think, because the language reflects the culture and is subject to cultural constraints. In different cultures, the same words can have different cultural meanings. For example, there are the concepts of bats in both English and Chinese language. In western culture, bats are ugly, evil and bloodsucking image, and the bat-related words are mostly pejorative. "As blind as bats" (someone is as blind as a bat) means someone has bad judgment of 
someone else. "Crazy as a bat" means someone is as crazy as a bat. However, in Chinese culture, the bat is a symbol of good fortune, health and happiness. On the contrary, different words may have the same meaning. For example, in English "as timid as a hare" has the same meaning with “胆小如鼠” (as timid as a rat) in Chinese. Both of them mean someone is very timid.

To avoid the human factors, how to achieve cultural equivalence in translation is also determined by the following four factors: (1) Types of the original text. (2) The importance of cultural color in the original text. (3) The purpose of translation. (4) The reader type of the target text. According to linguist Bielefeld, language has three functions: Ideographic, informative and vocative functions. If the cultural phenomenon is more important and the color of the author is more obvious in the original text with the function of ideographic and the original text has authority, it is necessary to retain the original culture color in the translation as much as possible. If the original test is to introduce a kind of cultural phenomenon, then color culture plays pivotal role in the original text, then the translation shall retain the color culture as much as possible to transfer the cultural phenomenon. Interpretation and annotation can be used when necessary. Foreignization or domestication is not the only way to solve the problem. Of course, the purpose and the object of translation also determine the choice of cultural equivalence and how to achieve equivalence.

\section{Conclusion}

As a part of culture, language is not only the form of culture, but also a phenomenon of social culture. In the process of language communication, whether the people from two different countries or ethnic groups can communicate with each other does not only depend on their understanding of the language itself, but also depends on the understanding of the cultural implication which the language loads. As a part of culture, language is not only the form of culture, but also a phenomenon of social culture. And the exchange of different languages is the exchange of different cultures. From this point of view, the translation of language is essentially a cultural translation, one of the purposes of translation is to establish cultural equivalence between the source language and the target language. Because of the differences between languages, there are many cultural differences between different expressions, and the methods of establishing cultural equivalence in translation are also different. According to different circumstances,"alienation" or "domestication" methods can be adopted to solve the cultural differences in translation in order to achieve cultural equivalence. In the vast majority of cases, it is proved that there must be one cultural equivalence translation method that can be accepted by the target language readers. It is important that the translator shall always pay attention to the cultural factors in the source language and try to establish the culture equivalence in target language.

\section{References}

[1] Petrucci P. The Translation of Cinematic Discourse and the Question of Character Equivalence in $[\mathrm{J}]$. Multilingua: Journal of Cross-Cultural and Interlanguage Communication, 2012, 31(2):231-251.

[2] Plessis T D. Problems posed by cultural differences for translation equivalence in Afrikaans-Russian, and Russian-Afrikaans texts [J]. South African Journal of Linguistics, 1999:124-148.

[3] Mimura C, Griffiths P. A Japanese version of the Perceived Stress Scale: cross-cultural translation and equivalence assessment [J]. Bmc Psychiatry, 2008, 8(1):1-7.

[4] Arnold B R, Smith J L. Chapter 13 - Methodologies for Test Translation and Cultural Equivalence [J]. Handbook of Multicultural Mental Health, 2013:243-262.

[5] Arnold B R, Matus Y E. Chapter 7-Test Translation and Cultural Equivalence Methodologies for Use with Diverse Populations [J]. Handbook of Multicultural Mental Health, 2000:121-136. 
[6] Denis F, Trojak B, Rude N. Cross-cultural equivalence in translation of the oral health impact profile: how to interpret the final score? [J]. Community Dentistry \& Oral Epidemiology, 2016, 44(3):1263-1264.

[7] Mioara, Codleanu. Socio-cultural Specificity and Translation. Socio-culturally Charged Idioms and Cultural Equivalence [J]. Universitatea "Ovidius" Constanta. Analele Stiintifice. Seria Filologie, 2009(209):11.

[8] Zhang N. Study on Cultural Equivalence in Translation and Its Strategies [J]. Journal of Hefei University of Technology, 2010.

[9] Al H. Translation and Cultural Equivalence: A Study of Translation Losses in Arabic Literary Texts [J]. Masri.

[10]Brislin R W. Back-translation for cross-cultural research [J]. J Cross Cult Psychol, 1970, 1(3):185-216.

[11]Peña E D. Lost in Translation: Methodological Considerations in Cross - Cultural Research [J]. Child Development, 2007, 78(4):1255-64.

[12] Stevelink S A, van Brakel W H. The cross-cultural equivalence of participation instruments: a systematic review. [J]. Disability \& Rehabilitation, 2013, 35(15):1256-1268. 